\title{
Higher Education Coordination in the Background of Beijing - Tianjin -Hebei Regional Integration: Bottleneck and Breakthrough
}

\author{
Jie BAO and Yu WANG*
}

School of Humanities, Tianjin University of Finance and Economics, Tianjin, China

*Corresponding author

Keywords: Higher education, Coordination, Beijing-Tianjin-Hebei.

\begin{abstract}
Higher education coordination is expected to facilitate the regional integrated development of Beijing-Tianjin-Hebei in terms of human resources and intellectual support. The study analyzed the data collected from authority websites and field research in order to investigate the present situation of higher education coordination. Findings of the study show that unequal administrative status, uneven distribution of public services and resources are the major non-collaborative factors in higher education coordination. The study also seeks to explore the strategies for collaborative development of higher education from the perspective of government's macro-control mechanism, resource integration and public service mode.
\end{abstract}

\section{Introduction}

\section{Beijing-Tianjin-Hebei Regional Integration}

As the capital city of China, Beijing has been suffering from expanded population, crowded traffic, soaring house prices and polluted environment. Under such circumstances, Chinese President Xi Jinping held a symposium calling for integrated and coordinated development of Beijing, Tianjin and Hebei which covers a variety of areas including healthcare, education and the flow of talents. In 2015, the Outline of Collaborative Development of Beijing, Tianjin and Hebei Province was issued as a national plan, aiming to reduce Beijing's "non-capital” functions with the economy and cityscape restructured, promote the mechanism of regional coordinated development and build modernized new capital-circle, which emphasize on cooperation rather the competition.

\section{Higher Education Coordination and Regional Integrated Development}

Higher education coordination is part of and also one of the highlights of the coordinated development of Beijing-Tianjin-Hebei. By optimizing and sharing the educational resources in Beijing-Tianjin-Hebei region, pinpointing the roles of higher education institutions in these three areas and promoting the cooperation between higher education institutions and social organizations, the whole educational level in this region is expected to upgrade to a new level. The upgraded higher education will, in turn, promote regional development. Bluestone, through an empirical study, pointed out that higher education can promote regional economic development by producing well-qualified professional workforce with higher incomes who contribute more to the regional tax revenue.[1] Higher education coordination will provide the region with better workforce and advanced intellectual support.

\section{Non-collaborative Factors in Higher Education Coordination: the Bottleneck}

\section{Unequal Administrative Status}

Though locate in the same geographic area, Beijing, Tianjin and Hebei belong to three administrative divisions with unequal administrative status. Beijing is the capital city and has always been the political, economic and cultural center of the country. Tianjin is a direct-controlled municipality as well as a major port city of north China. Hebei is a provincial-level administrative region with 11 prefecture-level cities. In Beijing-Tianjin-Hebei integration, the city of Baoding in Hebei is always considered to be the sub-center, which literally indicates its position as secondary 
and complementary to the existing urbanization structure. However, the future planning for Beijing-Tianjin-Hebei integration should shift its focus from center plus sub-center model to equal development model, that is, by proper city orientation, urban specialization and effective cooperation, Beijing-Tianjin-Hebei will be heading towards equal development.[2]

\section{Uneven Distribution of Public Facilities and Services}

As the capital city, Beijing has the best public facilities and services in terms of provision for the senior, health care, transportation, education and so on. Citizens of Tianjin also enjoy a high level of public facilities and services. According to a social survey in 2012, Tianjin is one of the top ten cities with the most satisfactory public service.[3] According to push-pull theory, besides the pursuit of a higher pay, people who choose to migrate to another area also take better living conditions, better access to education and better social environment into consideration.[4] The advantageous public facilities and services have become a great attraction for talents in Beijing-Tianjin-Hebei region, causing a one-way flow of talents from Hebei to Beijing and Tianjin.

\section{Uneven Distribution of Educational Resources}

Distribution of Institutions of Higher Education. According to the data on Ministry of Education website, by 2017, Beijing has a total number of 91 regular institutions of higher education (independent college and junior college included), the number of which for Tianjin and Hebei is 57 and 122 respectively. To define all these regular institutions of higher education, there is a well-accepted hierarchical structure. "211" refers to the project of building 100 key universities in order to take up the new challenge of the 21 century. "985” project was proposed in May, 1998, aiming to build a number of world-class universities to help achieve China's modernization.[5] Distribution of " 211 " and "985" universities is one important indicator of higher education resources.

Table 1. Distribution of higher education institutions in Beijing, Tianjin and Hebei (2017)

\begin{tabular}{|l|l|l|l|l|l|}
\hline & No. of Institutions & No. of “211” & No. of “985” & 211 ratio & 985 ratio \\
\hline Beijing & 91 & 26 & 9 & $28.6 \%$ & $9.9 \%$ \\
\hline Tianjin & 57 & 3 & 2 & $5.3 \%$ & $3.5 \%$ \\
\hline Hebei & 122 & 1 & 0 & $0.8 \%$ & 0 \\
\hline
\end{tabular}

Source of data: Ministry of Education website

From the statistics, huge gap can be been seen among Beijing, Tianjin and Hebei. In terms of elite cultivating, Hebei, with the largest total population has the least share of key universities, while Beijing, occupies the lion's share of high-quality higher education resources. In terms of higher education penetration, though Hebei has the largest number of higher education institutions, its total population is four times larger than Beijing and nearly five times larger than Tianjin.

Distribution of Teacher Resources. Due to the enrollment expansion in higher education, the upsurge in the number of students has lead to a lower teacher-student ratio. According to China statistical yearbook, Beijing has better resources of teaching staff in terms of teacher-student ratio and teacher's professional title.

Table 2. Number and title of college teachers in Beijing, Tianjin and Hebei (2012)

\begin{tabular}{|l|l|l|l|l|l|}
\hline & Total & Professor & Associate Professor & Lecturer & No. of enrolled students \\
\hline Beijing & 60852 & 13091 & 21089 & 22064 & 158602 \\
\hline Tianjin & 29929 & 4405 & 9673 & 11594 & 137223 \\
\hline Hebei & 65043 & 8575 & 18408 & 25488 & 321407 \\
\hline
\end{tabular}

Source of data: China statistical yearbook

Scientific research ability is another standard for teacher evaluation in higher education institutions. According to university evaluation report in 2015[6], Beijing has the most high-quality teaching staff in terms of academic level compared with Tianjin and Hebei. 
Table 3. Academic level of college teachers in Beijing, Tianjin and Hebei (2015) (independent college and junior college not included)

\begin{tabular}{|l|l|l|l|l|}
\hline & Grade & Number of institution & Average academic level & Human input \\
\hline Beijing & $\mathrm{A}++$ & 55 & 2.1796 & 71006 \\
\hline Tianjin & $\mathrm{B}+$ & 19 & 1.3613 & 22126 \\
\hline Hebei & $\mathrm{E}+$ & 30 & 0.4048 & 32135 \\
\hline
\end{tabular}

Source of data: 2015 University Evaluation Report

Teachers are the foundation of higher education that directly influences the quality of talents cultivation and scientific research. The uneven distribution of teacher resources will further enlarge the gap of higher education quality in Beijing, Tianjin and Hebei.

Educational Fund. Higher education institutions are considered to be the "talent pool" with two major functions: attracting talents and cultivating talents. Huge funds are needed to perform these two functions. Considering the fact that most universities and colleges in China are public, their major incomes come from state budget, tuition, and a small amount of industry income and donation. The study compared the state budget of higher education institutions in Beijing, Tianjin and Hebei since state budget is the biggest source of income for public schools.

Table 4. Educational fund allocated by government (2014)

\begin{tabular}{|c|c|c|}
\hline & Education fund (RMB yuan) & Rank \\
\hline Beijing & 66.9 billion & 1 \\
\hline Tianjin & 15.3 billion & 16 \\
\hline Hebei & 14.3 billion & \\
\hline
\end{tabular}

Source of data: China statistical yearbook

The table shows clearly that Beijing has the largest government fund in the country. Tianjin and Hebei reaches the average level with less than one fourth of the fund of Beijing. The imbalance poses a great challenge for higher education coordination in Beijing-Tianjin-Hebei region.

\section{Strategies for Higher Education: the Breakthrough}

\section{Government’s Macro-control Mechanism}

Breaking down the administrative barriers requires government's top design. Since the integrated and coordinated development of Beijing-Tianjin-Hebei has become a national strategy, the government should work out a long term mechanism to promote higher education coordination. First, a standing organization beyond the local governments should be built to focus on the policies and affairs of regional coordination and members of this organization should communicate on a regular basis. Favorable policies by central and local governments should be laid down and carried out to promote education layout adjustment and sharing of intellectual resources and educational achievements. In November, 2009, the paper Six Cooperation Intention reached by Education Commission of Beijing, Tianjin and Hebei on Higher Education Development put forward a coordination mechanism of regular discussion on cooperation and work focus. In April of 2011, governments of Beijing, Tianjin and Hebei signed the Talent Cooperation Framework Protocol in Beijing-Tianjin-Hebei region, aiming to realize the free flow of talent and the optimization of layout through policy coordination, coherent government system and connective services.[7] Second, local governments of Beijing, Tianjin and Hebei should go beyond the conventional practice of "minding its own business" and remove local protectionism. Effective lateral intergovernmental cooperation mechanism should be build to promote the exchange and cooperation among regional higher education institutions. Third, a sound security mechanism should be built to supervise the implementation of polices. The agreements and letters of intent signed by the local governments of Beijing, Tianjin and Hebei should be followed up by a series of down-to-earth practices.

\section{Resource Integration}

According to resource independence theory, the resources one organization needs are often in the hand of other organizations and independent organizations can therefore depend on each other. Despite the uneven distribution of educational resources in Beijing, Tianjin and Hebei, each of these 
three parties in the region can benefit itself as well as the overall development of the whole region from proper resource sharing and integration.

Complementary Advantages. Even though Beijing holds a safe lead in the region, Tianjin and Hebei also have their comparative advantages. Tianjin is a traditional municipality with strong comprehensive strength. Its geographically advantage reduces the cost of project cooperation with Beijing. In recent years, quite a few university towns were built in Tianjin. Haihe Education Park and Health Care Industry Park were built to supplement the traditional university towns in Tianjin. Achievement transformation center for scientific and technological innovation in higher education institutions built by the Ministry of Education and government of Tianjin has made some progress. Graduates of higher vocational colleges now enjoy preferential policy in terms of settlement in Tianjin.[8] By making good use of education infrastructures and favorable residency policy, Tianjin is fully capable of undertaking the spillover of talents and resources from Beijing. Though being in a disadvantageous position in terms of both key universities and regular universities, Hebei actually has quantity predominance in terms of higher vocational education. With part of Beijing's industry moving into Hebei and the urbanization process in Hebei, advanced skilled talents are in great need. Hebei can make the most of its comparative edges and put priority on the development of vocational education by cooperating and uniting with vocational colleges in Tianjin and Beijing.

Win-win Cooperation Mechanism. Institutions of higher education in Beijing-Tianjin-Hebei region should seek for closer cooperation in every field so as to achieve effective sharing of education resources. First, effective recourse sharing mechanism should be built to promote horizontal cooperation such as sharing of high-quality teachers, co-building of key laboratories and research centers and cooperative application of research subjects. Second, quality courses of different institutions in Beijing-Tianjin-Hebei region should be available to all the students in the region. Exchange program is a conventional way to share curriculum resources. But with the fast development of MOOC (Massive Open Online Course), curriculum sharing has become easier and cost-saving. Beijing University and Tsinghua University have the most influential MOOC platforms in China. Tianjin is gradually catching up with building MOOC platforms in Nankai University, Tianjin Foreign Language University, Tianjin Polytechnic University and Tianjin University of Sport. In Hebei, Hebei University, Hebei University of Science and Techonology, Hebei University of Technology and Hebei Institute of Media have also built their MOOC platforms.[9] The platforms in Beijing-Tianjin-Hebei are mostly for undergraduate education and courses available on these platforms are limited. If these platforms can be used in a larger scale, big breakthroughs can be expected in terms of resource sharing. Third, resource sharing should not be limited to the scale of higher education institutions. Trans-regional cooperation among higher education institutions, enterprises and research organizations should be strengthened to achieve efficient coordinated development of education and economy. By building industry-university-research parks, talents cultivation in higher institutions will be more targeted while enterprises could make full use of the human resources in higher education institutions and research organizations, which will promote innovation of products as well as technology. And because of the accumulative effect in the park, innovations in one organization will shed light on the whole area.

\section{Integration of Public Services}

To promote the flow of talents in Beijing-Tianjin-Hebei region, the level of public services is a crucial element. People choose their places of settlement in hope of a better living standard, a better health care system and better access to education. Government could consider relocating some of the public services in the region and gradually propel the synchronous development of public services in Beijin, Tianjin and Hebei.

\section{Conclusion}

The coordinated development of Beijing-Tianjin-Hebei is not simply a way to facilitate the development of the capital city, but a national strategy to promote a new growth mechanism based 
on mutual benefit and reciprocity. Higher education coordination is an important part of the national policy, which will in turn, benefit the regional integration and development plan. Along with the implementation of the policy, bottlenecks occur because of the difference of the three parties in administrative status, educational structure and development level. By optimizing administration and integrating education resources and public services, possible breakthroughs are foreseeable in the future.

\section{Acknowledgement}

This research was financially supported by Tianjin Philosophy and Social Science Foundation, China (TJYY17-025).

\section{References}

[1] Bluestone B, An Economic Impact Analysis, J. The Economic Journal. V1(1993)78-83.

[2] Jiahang Li, Fengqi Lin, A Study of the Coordinated Development of Beijing-Tianjin-Hebei from the Perspective of Resource Dependence Theory, C. Proceedings of the 9th Annual Meeting of Social Science in Hebei Province. (2014) 224-232.

[3] Shenming Li, Chongfu Li, Evaluation of Public Service in Chinese Cities (2011-2012), Social Sciences Academic Press, Beijing, 2012.

[4] E. Lee, A theory of migration, J. Demography. (1966) 47-57.

[5] File of “211" and “985” Institutions, J. Address Book of Enrollment (College Entrance Examination Volume). 1 (2006) 4.

[6] YongjunFeng, Deguo Zhao, Assessment Report of Chinese Universities (2015), Science Press, Beijing, 2015.

[7] Bateer Chen, Qi Zhang, Coordinated Development of Higher Education: A Great Driving Force for Beijin-Tianjin-Hebei Integration, J. China Higher Education. 23(2015) 15-17.

[8] Wei Zhang, Strategic Study of Tianjin's Development in Higher Education Coordination of Beijing-Tianjin-Hebei, C. Proceedings of the 10thAnnual Meeting of Social Science in Tianjin. (2014) 200-206.

[9] Ji Li, Mingling Li, Analysis on the Way to Facilitate Higher Education Collaborative Innovation in Beijing, Tianjin and Hebei Areas Based on Mooc, J. Journal of Tianjin Radio and TV University. 2(2017) 65-71. 